OPEN ACCESS

Check for updates

\title{
Autocratisation and universal health coverage synthetic control study
}

\author{
Simon Wigley, ${ }^{1}$ Joseph L Dieleman, ${ }^{2}$ Tara Templin, ${ }^{3}$ John Everett Mumford, ${ }^{2}$ Thomas J Bollyky ${ }^{4}$
}

${ }^{1}$ Department of Philosophy,

Bilkent University, Ankara, Turkey

${ }^{2}$ Institute for Health Metrics

and Evaluation, University of

Washington, Seattle, WA, USA

${ }^{3}$ Department of Medicine, Center for Health Policy, Stanford

University School of Medicine,

Stanford, CA, USA

${ }^{4}$ Global Health Program,

Council on Foreign Relations,

Washington, DC, USA

Correspondence to: S Wigley wigley@bilkent.edu.tr:

(ORCID 0000-0001-9181-0129)

Additional material is published online only. To view please visit

the journal online.

Cite this as: $B M J$ 2020;371:m4040

http://dx.doi.org/10.1136/bmj.m4040

Accepted: 16 October 2020

\section{ABSTRACT}

\section{OBJECTIVE}

To assess the relation between autocratisationsubstantial decreases in democratic traits (free and fair elections, freedom of civil and political association, and freedom of expression)-and countries' population health outcomes and progress toward universal health coverage (UHC).

\section{DESIGN}

Synthetic control analysis.

\section{SETTING AND COUNTRY SELECTION}

Global sample of countries for all years from 1989 to 2019, split into two categories: 17 treatment countries that started autocratising during 2000 to 2010 , and 119 control countries that never autocratised from 1989 to 2019. The treatment countries comprised low and middle income nations and represent all world regions except North America and western Europe. A weighted combination of control countries was used to construct synthetic controls for each treatment country. This statistical method is especially well suited to population level studies when random assignment is infeasible and sufficiently similar comparators are not available. The method was originally developed in economics and political science to assess the impact of policies and events, and it is now increasingly used in epidemiology.

\section{MAIN OUTCOME MEASURES}

HIV-free life expectancy at age 5 years, UHC effective coverage index (0-100 point scale), and out-of-pocket spending on health per capita. All outcome variables are for the period 1989 to 2019.

\section{WHAT IS ALREADY KNOWN ON THIS TOPIC}

Previous studies on the political determinants of health have focused on the impact of the overall quality of democracy on health spending, health service inputs, and population health outcomes

More countries are now experiencing substantial decreases in democratic traits (autocratising) than experiencing substantial increases in democratic traits (democratising)

Research is required on the relation between autocratisation and health outcomes

\section{WHAT THIS STUDY ADDS}

The findings of this study suggest that the ongoing wave of autocratisation is hindering progress in terms of life expectancy gains and the achievement of universal health coverage

The results indicate that global health institutions will need to adjust policy recommendations and activities to obtain the best possible outcomes in those countries where the democratic incentive to provide quality healthcare for all is diminishing

\section{RESULTS}

Autocratising countries underperformed for all three outcome variables in the 10 years after the onset of autocratisation, despite some improvements in life expectancy, UHC effective coverage index, and out-ofpocket spending on health. On average, HIV-free life expectancy at age 5 years increased by $2.2 \%$ (from 64.7 to 66.1 years) during the 10 years after the onset of autocratisation. This study estimated that it would have increased by 3.5\% (95\% confidence interval $3.3 \%$ to $3.6 \%, \mathrm{P}<0.001$ ) (from 64.7 to 66.9 years) in the absence of autocratisation. On average, the UHC effective coverage index increased by $11.9 \%$ (from 42.5 to 47.6 points) during the 10 years after the onset of autocratisation. This study estimated that it would have increased by $20.2 \%$ (95\% confidence interval $19.6 \%$ to $21.2 \%, \mathrm{P}<0.001$ ) (from 42.5 to 51.1 points) in the absence of autocratisation. Finally, on average, out-of-pocket spending on health per capita increased by $10.0 \%$ (from $\$ 4.00$ (£3.1; €3.4) to $\$ 4.4$, log transformed) during the 10 years after the onset of autocratisation. This study estimated that it would have increased by only $4.4 \%$ (95\% confidence interval $3.9 \%$ to $4.6 \%, \mathrm{P}<0.001$ ) (from $\$ 4.0$ to $\$ 4.2$, log transformed) in the absence of autocratisation.

\section{CONCLUSIONS}

Autocratising countries had worse than estimated life expectancy, effective health service coverage, and levels of out-of-pocket spending on health. These results suggest that the noticeable increase in the number of countries that are experiencing democratic erosion in recent years is hindering population health gains and progress toward UHC. Global health institutions will need to adjust their policy recommendations and activities to obtain the best possible results in those countries with a diminishing democratic incentive to provide quality healthcare to populations.

\section{Introduction}

For the first time since World War II, there are now more countries autocratising, or experiencing a substantial decline in democratic traits, than there are nations democratising. ${ }^{1}$ The number of autocratising countries began to increase sharply at the turn of the 20th century and especially after the 2008 financial crisis. In some countries, such as Nicaragua and Turkey, the process of autocratisation has advanced to the point that these nations are now considered electoral autocracies-countries in which elections are held only under conditions that prevent opposition parties from fairly campaigning and votes are prevented from being freely cast or accurately counted. In other nations, the process is more gradual and ongoing. According to 
one leading estimate, $35 \%$ of the world's population now live in countries that are autocratising-a list that includes Brazil and the United States. ${ }^{2}$

The ongoing wave of autocratisation might hinder progress towards universal health coverage (UHC). UHC is a critical means of improving population health and ensuring all people have access to quality essential health services, without incurring undue financial hardship. This is seen as a policy priority by global institutions and individual countries, as highlighted by the fact that UHC is included in the World Health Organization's 13th General Program of Work (GPW13) and the United Nations' Sustainable Development Goals. $^{34}$ The stated aim of the latter is to achieve UHC for the entire population of the world by 2030 (Sustainable Development Goals target 3.8). UHC is expensive and inherently redistributive, which makes it unavoidably a political choice. ${ }^{5}$ The achievement of UHC in each country will, to a large extent, depend on whether political leaders are willing to match health services with healthcare needs, and that in turn is likely to be influenced by the way in which those leaders are selected and held to account. Existing research indicates that democratic traits-open communication coupled with genuinely competitive multiparty elections-incentivise governments to respond to the health needs of citizens. ${ }^{6-8}$ Democratically elected leaders must win the support of a larger share of the population than autocratic leaders to stay in power. In addition, the greater openness of communication that typically characterises democratic societies means political leaders are more likely to be made aware of the need for health interventions, as well as the success or failure of those interventions. ${ }^{910}$ Autocratisation poses a threat to the achievement of quality healthcare for all because it involves the gradual contraction of the support base required by political leaders to stay in power and the steady erosion of media freedom and free speech more generally. ${ }^{210}$

We examined the association between substantial decreases in democratic traits and population health gains, the effective delivery of UHC, and financial risk protection. Specifically, we examined the association between democratic erosion (autocratisation) and life expectancy, UHC (measured using the effective coverage index), and healthcare costs borne by individuals. We hypothesised that autocratisation slows progress in life expectancy, hinders progress towards UHC, and increases out-of-pocket spending on healthcare.

\section{Methods}

Approach

We used a synthetic control design, an approach especially well suited to population level studies when random assignment is impractical and a data driven approach is needed to construct appropriate comparison cases. ${ }^{11}$ For each autocratising country, we estimate the trajectory that the outcome variable would have followed in the absence of autocratisation and compared that trajectory with the actual trajectory to estimate the potential impact of autocratisation. The counterfactual, or synthetic control, is constructed based on a weighted combination of those countries that were never exposed to the treatment of interest (ie, autocratisation). If the synthetic control closely tracks the actual trajectory during the pretreatment period, then we can have greater confidence in the validity of the estimated counterfactual trajectory during the post-treatment period. The important advantage of this approach is that it obviates the need to identify individual comparison countries that are sufficiently similar to the treatment countries. ${ }^{12}$

The synthetic control method has become widely used in the social sciences since it was originally developed in 2003. ${ }^{1314}$ The method is also increasingly used in epidemiology to assess the impact of public health interventions, such as anti-tobacco polices, taxes on soft drinks, handgun laws, social welfare reforms, hospital performance incentives, and pill mill laws (ie, legislation designed to tackle clinics that inappropriately prescribe and dispense prescription drugs). ${ }^{15-22}$ In addition, the method has been previously used ${ }^{623}$ to assess the impact of transitions from autocracy to democracy on, respectively, child mortality and adult life expectancy. Here we adopt the same general strategy to assess the association between autocratisation and HIV-free life expectancy at age 5 years, UHC effective coverage, and out-of-pocket spending on healthcare.

The version of the synthetic control method that we use constructs the counterfactual in three steps. ${ }^{24}$ Firstly, a fixed number of latent factors are estimated using the control group (those countries that did not experience autocratisation). Secondly, those factors are weighted to model the path of each outcome variable during the pretreatment period (the period before the start of each autocratisation episode). Thirdly, that model is used to estimate the counterfactual path of the outcome variable during the post-treatment period. Confidence intervals are estimated based on how reliably the model predicts the path of each control country when each is assumed to be a treated country. This method is described in more detail in the supplementary appendix. The analysis was carried out using the R platform (version 4.0.2), with the functions provided by the gsynth package (version 1.1.6). ${ }^{24}$

This approach accounts for time varying and time invariant confounders because the counterfactual, or synthetic control, implicitly captures the underlying characteristics of each treatment country that are associated with the health outcome. This method does not, however, account for shocks that occur at precisely the same time as the treatment. For this reason, we include three variables to control for shocks due to natural disasters, onset of war, and economic recession. A further concern is that autocratisation might contaminate countries in the control group because of the emigration of healthier citizens from autocratising countries. To deal with this possibility we included an indicator for net migration in the model. 
To identify episodes of autocratisation we used a procedure that has been independently developed. ${ }^{1}$ Namely, a 0.1 decrease in the electoral democracy index (scaled between 0 and 1) constructed by the Varieties of Democracy (V-Dem) project. ${ }^{25}$ We also stipulated that the confidence intervals for the index should not overlap between the beginning and the end of the episode. This enabled us to identify episodes that are both substantial and statistically significant, thereby reducing the likelihood of misidentification. This procedure is described in more detail in the appendix.

The procedure allowed us to identify 17 countries that underwent autocratisation during 2000 to 2010. We removed from the study those countries that first autocratised during the 10 years before or after that period to ensure sufficient pretreatment data to build the counterfactual and sufficient post-treatment years to observe any potential effects. The control group used to construct each counterfactual comprises the 119 countries that never autocratised from 1989 to 2019. All the treatment countries are low or middle income and include all regions of the world except North America and western Europe (fig 1). Eleven of those countries were electoral democracies the year before autocratisation, whereas the remainder were electoral autocracies. These countries are described in more detail in the supplementary appendix.

Data

The V-Dem constructs indictors of regime characteristics based on the responses of experts from multiple countries. We used version 10 of the V-Dem dataset, which encompasses 201 countries from 1789 to $2019 .{ }^{25}$ The dataset includes confidence intervals for each indicator to account for uncertainty and potential measurement error. To identify episodes of autocratisation we use the electoral democracy index, which combines scores for suffrage, free and fair elections, elected officials, freedom of civil and political organisation, and freedom of expression, to create an overall score ranging from 0 to 1 .

We extracted HIV-free life expectancy at age 5 years from the Global Burden of Disease 2019 database. ${ }^{26}$ The Global Burden of Disease project estimates age specific and sex specific mortality from 1970 to 2019 in 204 countries. HIV-free life expectancy estimates life expectancy in each country had the HIV pandemic not occurred, excluding war, epidemics, and natural disasters. We used HIV-free life expectancy at age 5 years for this analysis to isolate and assess the relation between autocratisation and health, abstracting from the impacts of HIV on life expectancy. Democratising and autocratising countries alike received substantial amounts of external development assistance for HIV/AIDS and communicable diseases that disproportionately affect child health, potentially masking the impact of democratic erosion. To assess whether variation exists across the life course we also report results for HIV-free life expectancy at birth and at age 15 years.

To measure UHC, we used the Institute for Health Metrics and Evaluation's UHC effective coverage index. This index uses data from the Global Burden of Disease 2019 and comprises 23 indicators that capture healthcare provision for conditions affecting population health across the life course. These indicators include several healthcare domains (prevention, promotion, treatment, rehabilitation, and palliative care). Each are weighted by the estimated potential for indicator specific interventions to reduce the associated health burden and then combined into an overall score, scaled between 0 and 100. This indicator is available for 204 countries for all years from 1990 to $2019 .{ }^{2728}$ One interpretation of the index is that a 1 point increase in a given country's UHC effective coverage index score reflects an estimated 1\% increase in that country's population with access to effective healthcare.

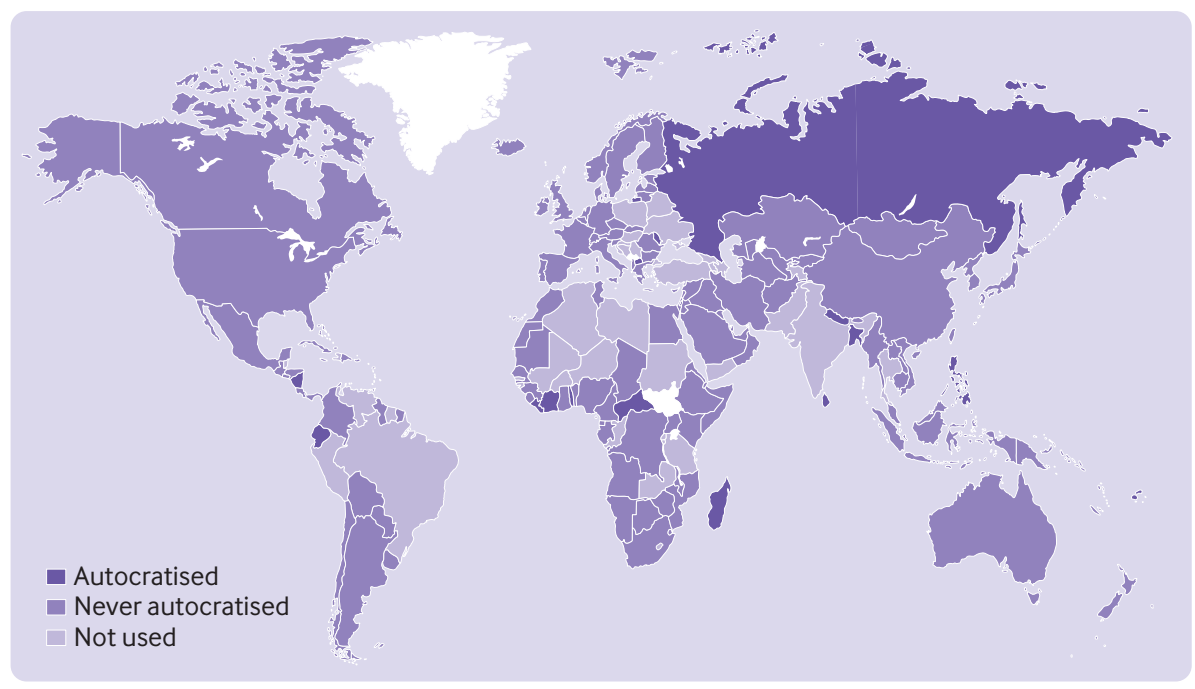

Fig 1 | Treated and control countries for synthetic control analysis 
We used the Institute for Health Metrics and Evaluation's Financing Global Health 2019 database for out-of-pocket spending on health. ${ }^{29}$ Data are available for 195 countries from 1995 to 2017. These estimates are developed by assembling and modeling data from WHO's Global Health Expenditure Database. We used 2019 purchasing power parity in US dollars adjusted for inflation.

Finally, we included three variables in our analysis to control for contemporaneous shocks: major natural disasters, war related deaths, and gross domestic product per capita. The indicator for natural disasters is based on the International Disaster Database compiled by the Centre for Research on the Epidemiology of Disasters. ${ }^{30}$ The indicator for mortality due to war is taken from the Global Burden of Disease 2019 Covariates database. ${ }^{31}$ Data on gross domestic product per capita are extracted from the Financing Global Health 2019 database. ${ }^{29}$ We used 2019 purchasing power parity in US dollars adjusted for inflation. We did not include these covariates in the life expectancy model because that outcome variable already excludes mortality shocks due to natural disasters and war. We included net migration as a covariate in all three models to control for the possibility that autocratisation leads to the emigration of healthier citizens to countries in the control group. The migration data were extracted from the UN Population Prospects. ${ }^{32}$

The supplementary appendix presents summary statistics for all variables, arranged by exposure category.
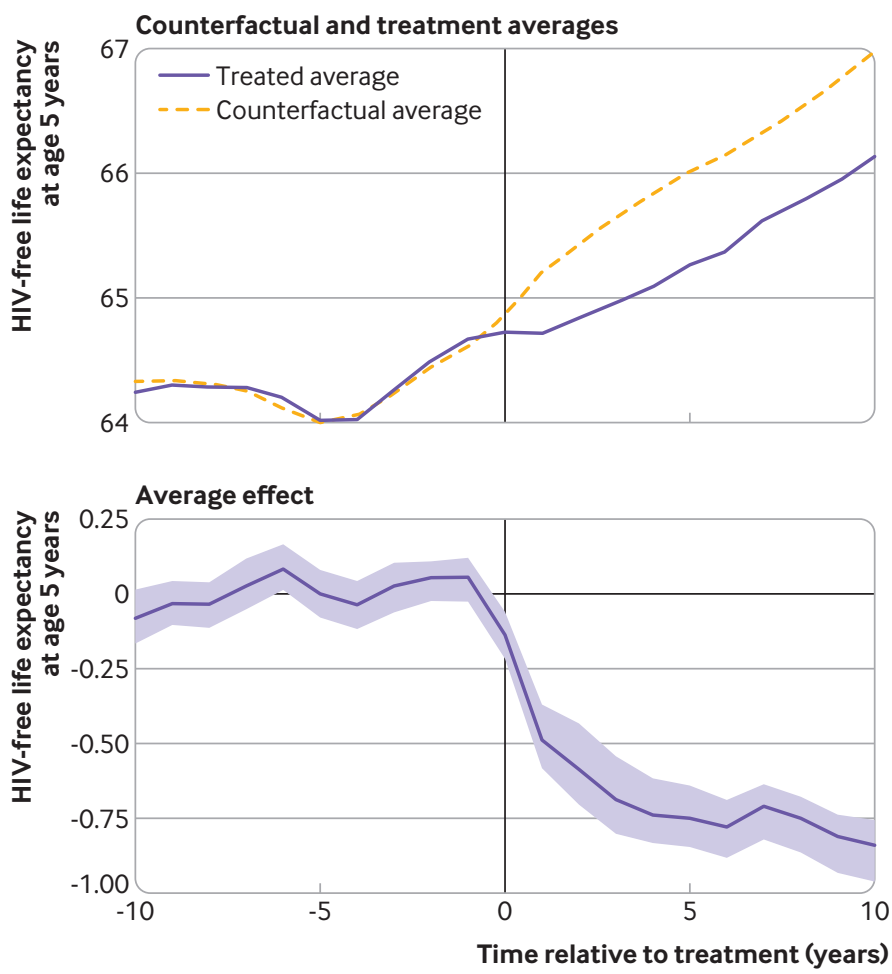

Fig 2 | Counterfactual averages, treatment averages, and average effects for HIV-free life expectancy at age 5 years in 17 autocratising countries, 1989-2019. Shading represents $95 \%$ confidence intervals

\section{Patient and public involvement}

Patients and members of the public were not involved in the design, analysis, or dissemination plans of our research. This is because our study relies on population level data for a large number of countries. We aim to share our findings through social media and blogs. All data used were retrieved from existing public sources, as referenced.

\section{Results}

In the autocratising countries included in the analysis, from 1995 to 2017 HIV-free life expectancy at age 5 years increased by $5.13 \%$ (from 63.8 to 67.1 years). Similarly, the UHC effective coverage index in these countries increased by $24.7 \%$ (from 40.7 to 50.7 points) and out-of-pocket spending on health per capita increased by $15.3 \%$ (from $\$ 3.8$ (£2.9; €3.2) to $\$ 4.5, \log$ transformed).

For each outcome variable figures 2-7 show the average treatment and counterfactual trajectories, the average treatment effect, and the effect for each treated country. The counterfactual trajectories track the treatment trajectories during the pretreatment period (figs 2, 4, and 6). The effect plots represent the gap between the treatment and counterfactual trajectories and include $95 \%$ confidence intervals. For all three outcome variables the average gap between actual and counterfactual was statistically significant from the first year after the onset of autocratisation.

Our results show that on average HIV-free life expectancy at age 5 years increased by $2.2 \%$ (from 64.7 to 66.1 years) during the 10 years after the onset of autocratisation. Our estimation suggests that it would have increased by 3.5\% (95\% confidence interval $3.3 \%$ to $3.6 \%, \mathrm{P}<0.001$ ) (from 64.7 to 66.9 years) in the absence of autocratisation. This is a difference of 10 months between those countries that autocratised and what we estimate they would have gained had they not autocratised (fig 2).

On average, the UHC effective coverage index increased by $11.9 \%$ (from 42.5 to 47.6 points) during the 10 years after the onset of autocratisation. Our estimation suggests that it would have increased by $20.2 \%$ (95\% confidence interval $19.6 \%$ to $21.2 \%$, $\mathrm{P}<0.001$ ) (from 42.5 to 51.1 points) in the absence of autocratisation (fig 4).

Finally, out-of-pocket spending on health per capita increased on average by $10.0 \%$ (from $\$ 4.0$ to $\$ 4.4$, $\log$ transformed) during the 10 years after the onset of autocratisation. Our estimation suggests that it would have increased by only $4.4 \%$ (95\% confidence interval 3.9\% to $4.6 \%, \mathrm{P}<0.001$ ) (from $\$ 4.0$ to $\$ 4.2$, log transformed) in the absence of autocratisation (fig 6).

Autocratisation was associated with underperformance in most of the countries in the treatment group (13 to 15 out of 17 , depending on the outcome variable) (figs 3, 5, and 7). The largest underperformance after 10 years was observed in the Philippines for UHC effective coverage (a 3.4\% decrease compared with a $26.6 \%$ increase for the counterfactual, 95\% confidence interval $23.6 \%$ to 

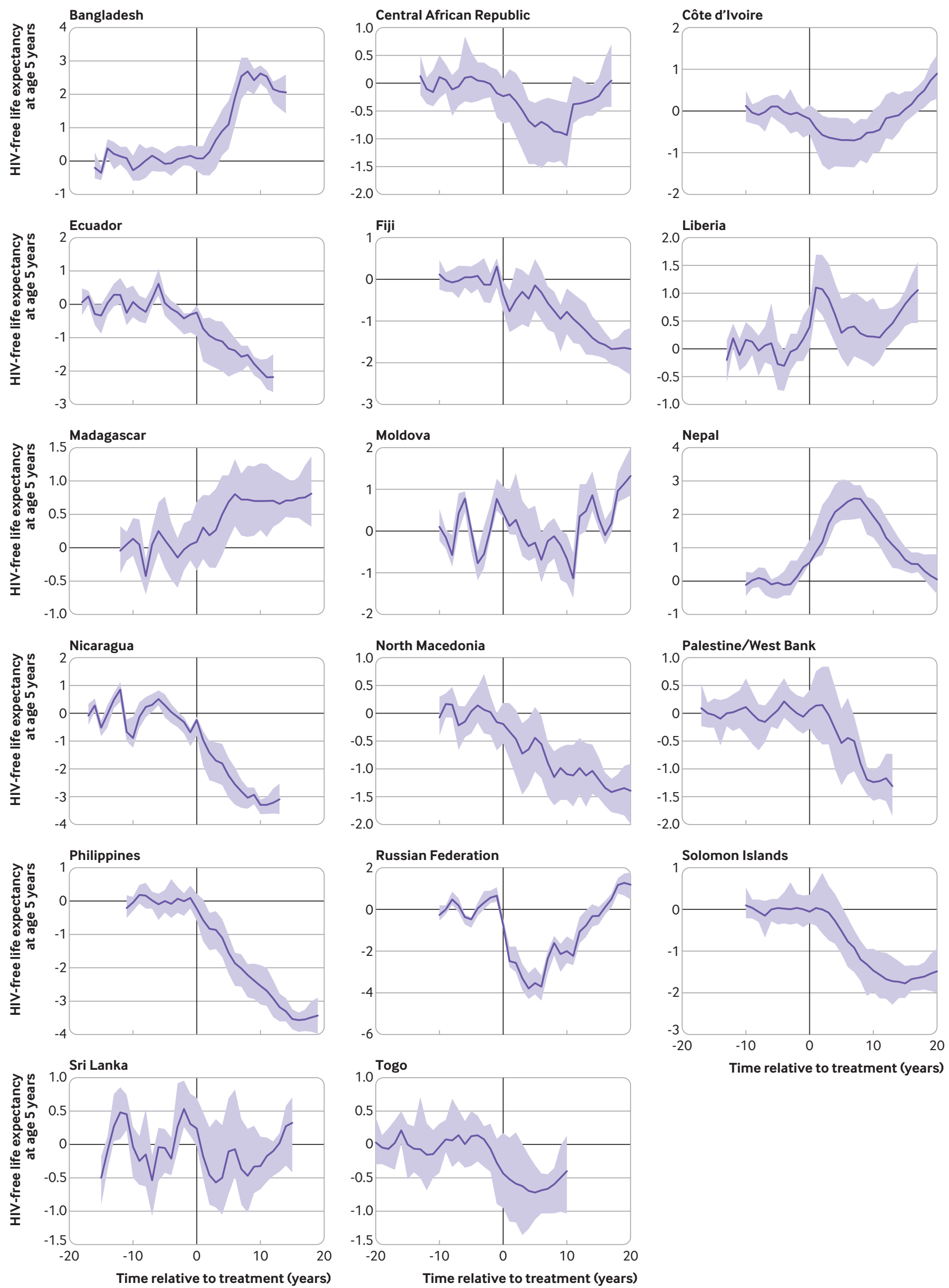

Fig 3 | Effects for HIV-free life expectancy at age 5 years in 17 autocratising countries, 1989-2019. Shading represents $95 \%$ confidence intervals 

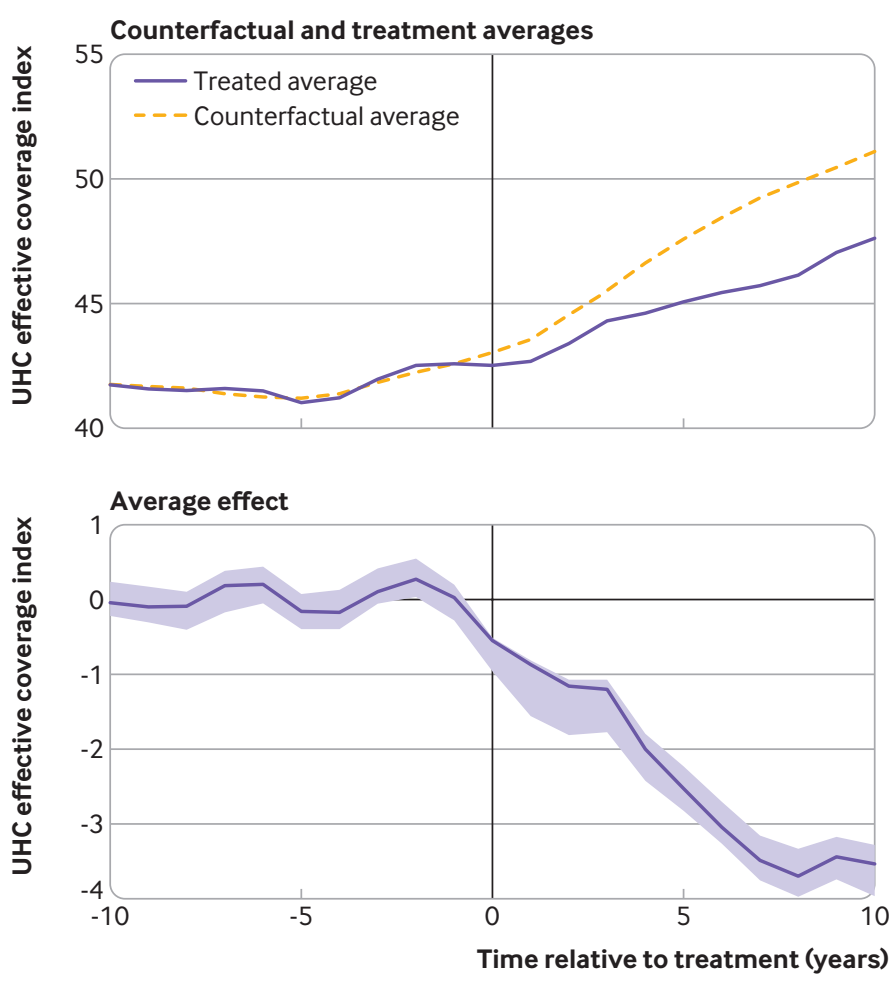

Fig 4 | Counterfactual averages, treatment averages, and average effects for effective universal health coverage (UHC) in 17 autocratising countries, 1989-2019. Shading represents $95 \%$ confidence intervals
29.3\%, P<0.001), Moldova for out-of-pocket spending on health (a 30.2\% increase compared with a $8.8 \%$ increase for the counterfactual, 95\% confidence interval $6.8 \%$ to $10.4 \%, \mathrm{P}<0.001$ ), and Nicaragua for HIV-free life expectancy at age 5 years (a $0.1 \%$ decrease compared with a $4.3 \%$ increase for the counterfactual, $95 \%$ confidence interval $4 \%$ to $4.7 \%$, $\mathrm{P}<0.001)$. However, not all countries underperformed. Nepal, for example, initially performed better than the counterfactual across all three outcome variables.

Out-of-pocket spending on health per capita might increase in those countries where health services are emerging or decrease in those countries with contracting health services. ${ }^{33}$ To control for these possibilities we ran the model with share of outof-pocket spending in total health expenditure (government health expenditure, prepaid private, development assistance for health, and out of pocket) as the outcome variable. The result was consistent with our original finding. We also examined whether autocratisation was associated with the provisioning of development assistance for health per capita. We found no evidence that democratic deterioration affected the disbursement of health related aid. Both these additional results are presented in the supplementary appendix.

\section{Discussion}

In general, this study found that autocratising states performed worse than they would have if they had not experienced democratic erosion. HIV-free life expectancy at age 5 years was on average 1.3\% (95\% confidence interval $1.1 \%$ to $1.4 \%, \mathrm{P}<0.001$ ) lower than the synthetic control after 10 years. The effect on HIV-free life expectancy at age 15 years was slightly larger (1.6\% lower, 95\% confidence interval $1.4 \%$ to $1.8 \%, \mathrm{P}<0.001$ ), whereas the effect on HIV-free life expectancy at birth was smaller, but still statistically significant $(0.5 \%$ lower, $95 \%$ confidence interval $0.4 \%$ to $0.7 \%, \mathrm{P}<0.001)$. These additional results are presented in the supplementary appendix. In keeping with global trends, ${ }^{27}$ the Institute for Health Metrics and Evaluation's UHC effective coverage index did increase on average in autocratising countries during the post-treatment period. However, our results show that on average the index was 7.4\% (95\% confidence interval $6.9 \%$ to $8.3 \%, \mathrm{P}<0.001$ ) lower than the synthetic control after 10 years. Finally, we found that autocratisation tends be associated with increases in the healthcare costs incurred by individuals at the point of care. Out-of-pocket spending on health per capita was on average 5.1\% (95\% confidence interval $4.9 \%$ to $5.6 \%, \mathrm{P}<0.001)$ higher than the synthetic control after 10 years. This is noteworthy because increased household spending on health is associated with vulnerability to financial hardship, and financial risk protection is one of the UHC items specified in the Sustainable Development Goals (target 3.8.2). ${ }^{34}$ In the context of already severely constrained household budgets these additional costs could push people into poverty, especially if those costs cannot be spread over time. $^{33} 35$

For most of the 17 countries in our analysis, autocratisation was associated with reduced performance for our three outcome indicators. However, this was not the case for all countries. Liberia, Bangladesh, and especially Nepal represent notable exceptions and therefore warrant closer examination in future research. For those three countries the autocratisation period was followed by a rapid recovery to a democracy level higher than was the case before that period (see figure in supplementary appendix, section 3.2.3). This suggests that immediate and substantial democratic reform might negate the potential negative effects of autocratisation.

\section{Comparison with other studies}

Previous cross country studies on the political determinants of health have focused on the impact of the overall degree of democracy on healthcare spending, health service inputs, and population health outcomes. ${ }^{36-41}$ Some studies have examined the impact of autocratic regime types on health outcomes. ${ }^{42} 43$ Others have examined the effect of transitions from autocracy to democracy on health outcomes. ${ }^{6} 2344$ However, few have assessed the effects of democratic erosion (ie, autocratisation) on health outcomes and none have considered its effects on UHC.

Our findings are consistent with a recent study, ${ }^{6}$ which found that HIV-free life expectancy at age 15 years was on average $3 \%$ higher than the counterfactual of no democratic transition after 10 years. The 

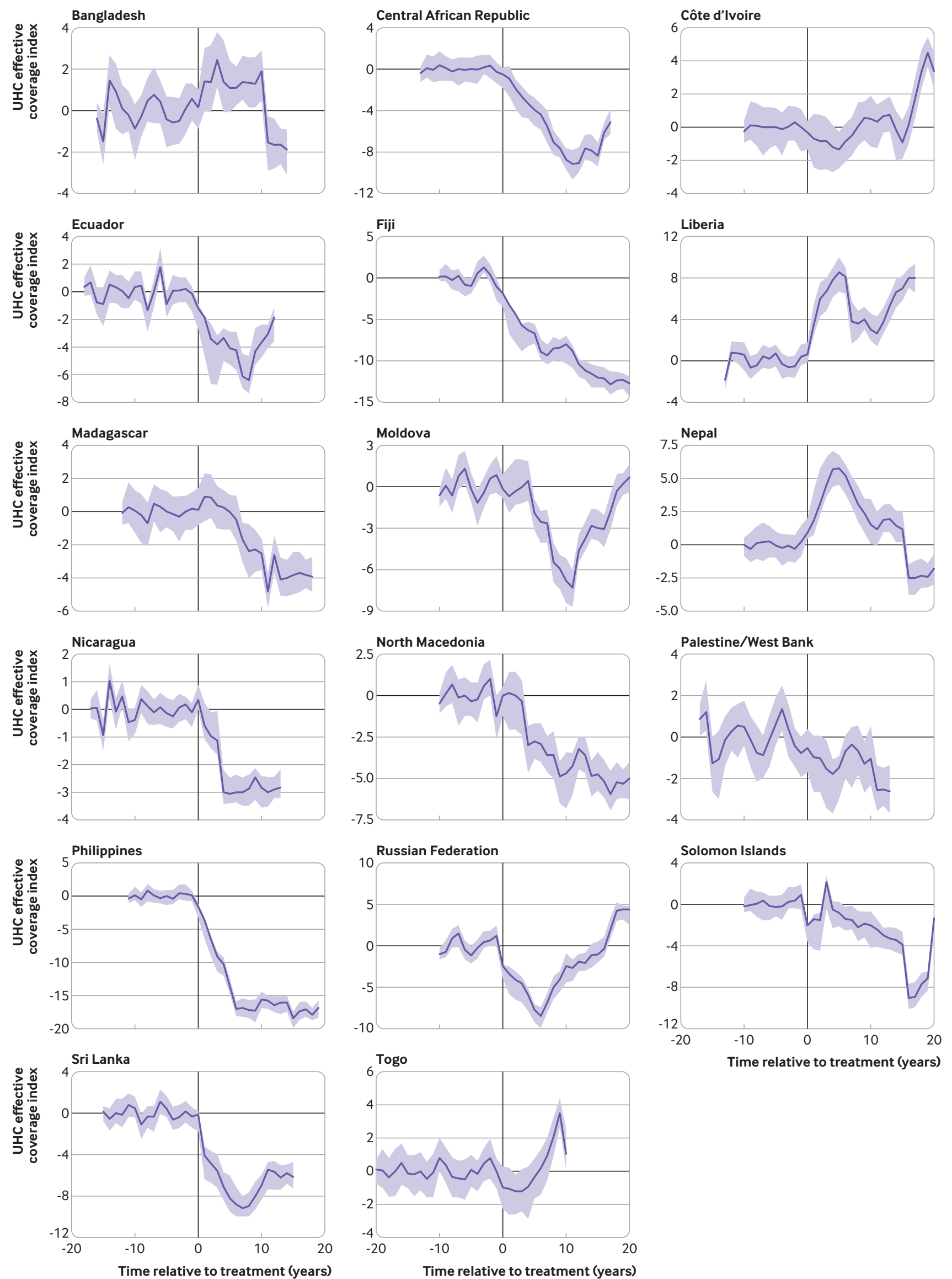

Fig 5 | Effects for universal health coverage (UHC) in 17 autocratising countries, 1989-2019. Shading represents $95 \%$ confidence intervals 

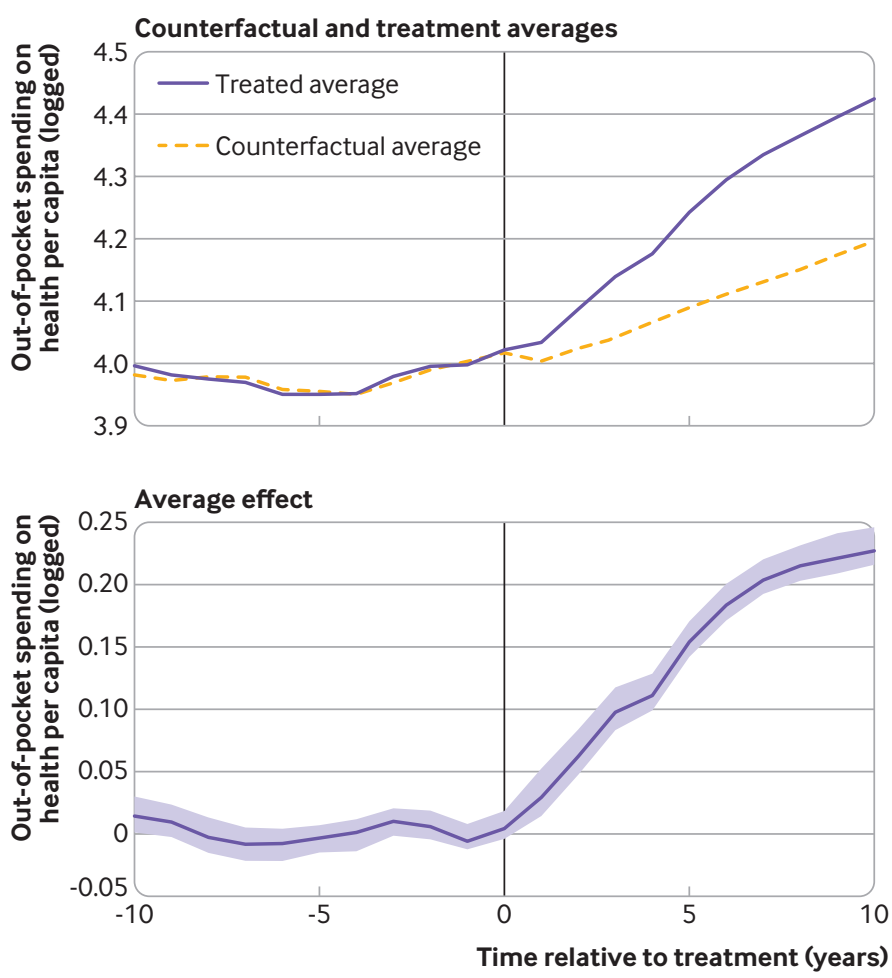

Fig 6 | Counterfactual averages, treatment averages, and average effects for outof-pocket spending on health per capita in 17 autocratising countries, 1989-2019. Shading represents $95 \%$ confidence intervals

earlier paper assessed transitions from autocracy to democracy, rather than substantial changes in the level of democracy that might or might not lead to transition. Nevertheless, the findings of both that study and our study support the view that autocratising governments are less equipped to tackle diseases that primarily affect the adult population. Those diseases typically require prevention policies and chronic care and receive little development assistance for health. ${ }^{6}$

\section{Strengths and limitations of this study}

Our findings are subject to two limitations. Firstly, our data sources (particularly life expectancy, effective UHC, and democracy) rely on an estimation process with assumptions. The Global Burden of Disease and Financing Global Health 2019 data are the best available and are validated against a diverse set of data sources, as well as the expertise of more than 5000 collaborators from 145 countries. The UHC effective coverage index is a composite score of specific measurement choices, including health outcomes and effective coverage of key interventions. Because some of these data were under-reported, the Global Burden of Disease project models these inputs, which ultimately inform the estimate of UHC. If the original data sources are systematically inflated to make autocracies look better than they are (longer life expectancy, less outof-pocket spending, more UHC service coverage), the estimated associations presented in this study would then represent underestimates of the true effect.
Additionally, the V-Dem project relies on the responses of experts from multiple countries to a range of precise survey questions to construct estimates of regime traits. The nature of the indicators means that measurement error will occur if respondents are subject to bias, use different rating thresholds, or make a mistake. The compilers of the V-Dem dataset include confidence intervals to account for those potential sources of error. We used those uncertainty estimates as part of the process to identify autocratisation episodes. Nevertheless, we cannot rule out the possibility that we have incorrectly identified treatment cases.

Secondly, causality is difficult to ascertain in this context because population health could affect democratic traits, ${ }^{45}$ and omitted factors might separately determine those traits and health indicators. The method we used in this study estimates the effect of autocratisation by creating a synthetic version of each autocratising country based on a weighted combination of those countries that did not experience autocratisation. This allows greater confidence in causal inference insofar as the modeling process reliably estimates the path of the treated countries during the pretreatment period. Nevertheless, the results could be confounded if shocks occur at precisely the same time as the treatment of interest, or the treatment contaminates the control group (eg, migration of heathier people from autocratising to nonautocratising states). We have included covariates to deal with these two possibilities. We cannot, however, rule out the possibility that other coinciding events or spillover effects are driving the results.

\section{Policy implications}

Overall, our findings suggest that global health institutions and non-governmental organisations will find it increasingly difficult to achieve the Sustainable Development Goals for health, particularly UHC, in settings as democratic erosion modifies the willingness and capacity for governments to respond to the health needs of citizens. In some cases, erosion results in political regimes that merely pay lip service to democracy. Since the end of the cold war the approach of many autocratic leaders is to permit elections and opposition parties, but to ensure ongoing re-election through control of media, intimidation and prosecution of members of the opposition, and various forms of electoral fraud. ${ }^{46}$ In effect this means that supporters of the opposition are disenfranchised.

Our results have important implications for the allocation of development assistance for health, especially where those resources are intended to advance effective UHC and financial risk protection. That development assistance for health is scarce and, amid a post-pandemic global economic downturn, it may contract further. It is more important than ever to consider where and how to spend development assistance for health more effectively. Donors seeking to advance effective UHC or financial risk protection should consider directing more of those funds to nations that have a commitment to building 

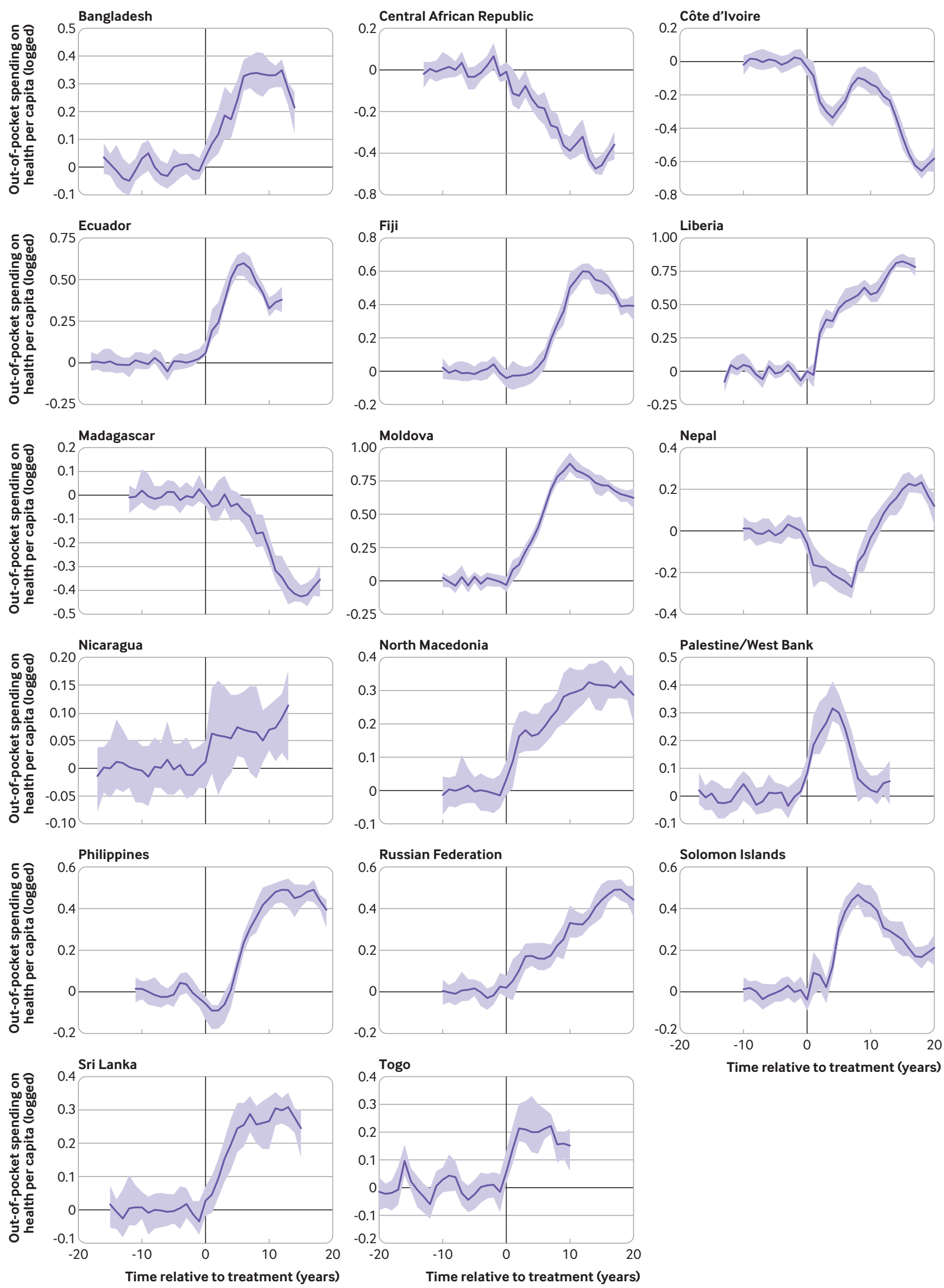

Fig 7 | Effects for out-of-pocket spending on health per capita in 17 autocratising countries, 1989-2019. Shading represents $95 \%$ confidence intervals 
accountable institutions and open and transparent democratic processes. The US Millennium Challenge Corporation and Swedish International Development Cooperation Agency have used similar selective approaches to aid to promote good governance in their programmes.

More generally, global institutions and aid providers might need to adjust their policy recommendations and activities so as to extract the best possible results in those countries where political leaders lack sufficient electoral incentives to provide quality healthcare to the population. A closer examination of why health service delivery and health outcomes in some countries do not appear to have been negatively affected by autocratisation (eg, Bangladesh and Nepal) might prove to be instructive in this regard. For example, in Bangladesh, increased out-of-pocket expenditure on health per capita could have purchased health services not provided by the public healthcare system, increasing effective coverage. ${ }^{47}$

\section{Future research}

Our analysis does not account for the 16 countries that have autocratised since 2010, for which there are insufficient data to include in the present study. This group comprises countries with large populations, such as Brazil, India, Poland, and Turkey, indicating the scale of the potential obstacles in the path of UHC. Follow-up research will be needed to determine whether autocratisation has also hindered progress towards UHC in those countries. In our study we investigated health system change, which could take years, whereas other studies could investigate acute health outcomes.

\section{Conclusion}

By definition UHC requires that the entire population of each country has access to quality essential healthcare across the life course, which would be clearly associated with gains in population health. UHC implicitly entails the redistribution of resources to poorer citizens who cannot afford quality essential services without experiencing financial hardship. The ongoing wave of autocratisation poses a threat to the achievement of UHC and gains in population health because political leaders who are not selected through genuinely competitive multiparty elections do not require the support of the wider population to stay in power. In addition, their narrow support base often lies with wealthier citizens who might be unwilling to finance healthcare for poorer citizens. The results presented in this study suggest that global health advocates will need to develop strategies that compensate for the diminishing incentive of autocratising governments to provide quality healthcare for all.

This article is part of a collection launched at the World Health Summit, 25-27 October 2020, Berlin, Germany. Funding for the articles, including open access fees, was provided by a grant from Bloomberg Philanthropies to the Council on Foreign Relations, support from the Konrad-Adenauer-Stiftung to the Graduate Institute of International and Development Studies, and the Institute for Health Metrics and Evaluation.
Contributors: SW, JLD, TT, JEM, and TJB conceived and designed the study and coauthored the manuscript. SW performed the statistical analysis and is responsible for the overall content of the article. SW is the guarantor. The corresponding author attests that all listed authors meet authorship criteria and that no others meeting the criteria have been omitted.

Funding: This research was financially supported by the Bill and Melinda Gates Foundation and Bloomberg Philanthropies. The funders had no role in determining the study design, collection or analysis of data, or interpretation of the results, and the decision to submit was solely that of the authors.

Competing interests: All authors have completed the ICMJE form at www.icmje.org/coi_disclosure.pdf and declare: support the Bill and Melinda Gates Foundation and Bloomberg Philanthropies; no financial relationships with any organisations that might have an interest in the submitted work in the previous three years, no other relationships or activities that could appear to have influenced the submitted work. Ethical approval: Not required.

Data sharing: The authors agree to provide the data and statistical code used in this study upon request.

The manuscript's guarantor (SW) affirms that the manuscript is an honest, accurate, and transparent account of the study being reported; that no important aspects of the study have been omitted; and that any discrepancies from the study as planned (and, if relevant, registered) have been explained.

Dissemination to participants and related patient and public communities: As this research uses health and political data at the country level, there are no plans for dissemination to specific participants. We do, however, plan to share our findings through social media and blogs. This will allow us to direct interested parties to our open access research article and to facilitate discussion of our findings. In this way, we can involve everyone.

Provenance and peer review: Commissioned; externally peer reviewed.

Publisher's note: Published maps are provided without any warranty of any kind, either express or implied. BMJ remains neutral with regard to jurisdictional claims in published maps.

This is an Open Access article distributed in accordance with the Creative Commons Attribution Non Commercial (CC BY-NC 4.0) license, which permits others to distribute, remix, adapt, build upon this work non-commercially, and license their derivative works on different terms, provided the original work is properly cited and the use is noncommercial. See: http://creativecommons.org/licenses/by-nc/4.0/.

1 Lührmann A, Lindberg SI. A third wave of autocratization is here: what is new about it?Democratization 2019:26:1095-113. doi:10.1080/ 13510347.2019.1582029

2 Lührmann A, Maerz SF, Grahn S, et al. V-Dem Annual Democracy Report 2020. Autocratization Surges - Resistance Grows. Gothenburg: Varieties of Democracy Institute (V-Dem). 2020. www.vdem.net/en/publications/democracy-reports/ (accessed 14 Jun 2020)

3 World Health Organization. Thirteenth General Programme of Work 2019-2023: promote health, keep the world safe, serve the vulnerable. WHO, 2019

4 UN. Transforming our World: The 2030 Agenda for Sustainable Development. Sustainable Development Knowledge Platform. 2015. https://sustainabledevelopment.un.org/post2015/ transformingourworld/publication (accessed 14 Jun 2020).

5 Greer SL, Méndez CA. Universal Health Coverage: A Political Struggle and Governance Challenge. Am J Public Health 2015;105(Suppl 5):S637-9. doi:10.2105/AJPH.2015.302733

6 Bollyky TJ, Templin T, Cohen M, Schoder D, Dieleman JL, Wigley S. The relationships between democratic experience, adult health, and cause-specific mortality in 170 countries between 1980 and 2016: an observational analysis. Lancet 2019;393:1628-40. doi:10.1016/ S0140-6736(19)30235-1

7 Gerring J, Knutsen CH, Maguire M, et al. Democracy and human development: issues of conceptualization and measurement. Democratization 2020;1-25. doi:10.1080/13510347.2020. 1818721

8 McGuire JW. Democracy and Population Health. Cambridge University Press, 2020, accessed 14 Jun 2020 doi:10.1017/9781108778725

9 Sen A. Development as Freedom. Anchor Books, 1999.

10 Wigley S, Akkoyunlu-Wigley A. The impact of democracy and media freedom on under-5 mortality, 1961-2011. Soc Sci Med 2017;190:237-46. doi:10.1016/j.socscimed.2017.08.023

11 Bouttell J, Craig P, Lewsey J, Robinson M, Popham F. Synthetic control methodology as a tool for evaluating population-level health 
interventions. J Epidemiol Community Health 2018;72:673-8. doi:10.1136/jech-2017-210106

12 Abadie A, Diamond A, Hainmueller J. Comparative Politics and the Synthetic Control Method. Am J Pol Sci 2015;59:495-510. doi:10.1111/ajps.12116

13 Abadie A, Gardeazabal J. The Economic Costs of Conflict: A Case Study of the Basque Country. Am Econ Rev 2003;93:113-32. doi:10.1257/000282803321455188

14 Athey S, Imbens GW. The State of Applied Econometrics: Causality and Policy Evaluation. J Econ Perspect 2017;31:3-32. doi:10.1257/ jep.31.2.3

15 Abadie A, Diamond A, Hainmueller I. Synthetic Control Methods for Comparative Case Studies: Estimating the Effect of California's Tobacco Control Program. J Am Stat Assoc 2010;105:493-505. doi:10.1198/jasa.2009.ap08746

16 Chelwa G, van Walbeek C, Blecher E. Evaluating South Africa's tobacco control policy using a synthetic control method. Tob Control 2016;26:509-17. doi:10.1136/ tobaccocontrol-2016-053011

17 Fletcher JM, Frisvold DE, Tefft N. Non-linear effects of soda taxes on consumption and weight outcomes. Health Econ 2015;24:566-82. doi:10.1002/hec.3045

18 Crifasi CK, Meyers JS, Vernick JS, Webster DW. Effects of changes in permit-to-purchase handgun laws in Connecticut and Missouri on suicide rates. Prev Med 2015;79:43-9. doi:10.1016/j. ypmed.2015.07.013

19 Kagawa RMC, Castillo-Carniglia A, Vernick JS, et al. Repeal of Comprehensive Background Check Policies and Firearm Homicide and Suicide. Epidemiology 2018;29:494-502. doi:10.1097 EDE.0000000000000838

20 Basu S, Rehkopf DH, Siddiqi A, Glymour MM, Kawachi I. Health Behaviors, Mental Health, and Health Care Utilization Among Single Mothers After Welfare Reforms in the 1990s. Am Epidemiol 2016;183:531-8. doi:10.1093/aje/kwv249

21 Brighthaupt SC, Stone EM, Rutkow L, McGinty EE. Effect of pill mill laws on opioid overdose deaths in Ohio \& Tennessee: A mixedmethods case study. Prev Med 2019;126:105736. doi:10.1016/j. ypmed.2019.05.024

22 Kreif N, Grieve R, Hangartner D, Turner AJ, Nikolova S, Sutton M. Examination of the Synthetic Control Method for Evaluating Health Policies with Multiple Treated Units. Health Econ 2016;25:1514-28. doi:10.1002/hec.3258

23 Pieters H, Curzi D, Olper A, Swinnen J. Effect of democratic reforms on child mortality: a synthetic control analysis. Lancet Glob Health 2016;4:e627-32. doi:10.1016/S2214-109X(16)30104-8

24 Xu Y. Generalized Synthetic Control Method: Causal Inference with Interactive Fixed Effects Models. Polit Anal 2017;25:57-76 doi:10.1017/pan.2016.2

25 Coppedge M, Gerring J, Knutsen CH, et al. V-Dem Dataset V10. Varieties of Democracy Institute 2020. doi:10.23696/vdemds20 (accessed 6 Jun 2020)

26 Global Burden of Disease Collaborative Network. Global Burden of Disease Study 2019 (GBD 2019) All-cause Mortality and Life Expectancy 1950-2019. Seattle, United States: Institute for Health Metrics and Evaluation (IHME), University of Washington 2020. http://ghdx.healthdata.org/gbd-2019 (accessed 20 July 2020).

27 Lozano R, et al. Measuring the effective coverage index for universal health coverage in 204 countries and territories, 1990-2019: a systematic analysis for the Global Burden of Disease Study 2019. Lancet 2020; published online 27 August. doi:10.1016/S01406736(20)30750-9

28 Bill \& Melinda Gates Foundation. 2020 Goalkeepers Report. Bill \& Melinda Gates Foundation 2020. https://www.gatesfoundation.org/ goalkeepers/report/2020-report/ (accessed 20 July 2020)

29 Global Burden of Disease Collaborative Network. Global Health Spending 1995-2017. Seattle, United States: Institute for Health
Metrics and Evaluation (IHME), University of Washington 2020. http://ghdx.healthdata.org/record/ihme-data/global-healthspending-1995-2017 (accessed 6 Jun 2020).

30 Guha-Sapir D. EM-DAT. The Emergency Events Database. Brussels, Belgium: Université catholique de Louvain (UCL) - CRED 2020. www. emdat.be/database (accessed 6 Jun 2020).

31 Global Burden of Disease Collaborative Network. Global Burden of Disease Study 2019 (GBD 2019) Covariates 1980-2019. Seattle, United States: Institute for Health Metrics and Evaluation (IHME), University of Washington, 2020. http://ghdx.healthdata. org/record/global-burden-disease-study-2019-gbd-2019covariates-1980-2019 (accessed, 20 July 2020).

32 World Population Prospects UN. 2019 (Online Edition. Rev. 1.). United Nations, Department of Economic and Social Affairs, Population Division, 2019, https://population.un.org/wpp/ Download/Standard/Migration/ (accessed 27 Jun 2020).

33 Wagstaff A, Flores G, Hsu J, et al. Progress on catastrophic health spending in 133 countries: a retrospective observational study. Lancet Glob Health 2018;6:e169-79. doi:10.1016/S2214109X(17)30429-1

34 UN Statistical Commission. SDG Target 3.8.2 metadata. SDG Indic. 2019. https://unstats.un.org/sdgs/metadata/files/ Metadata-03-08-02.pdf (accessed 15 Jun 2020).

35 Wagstaff A, Flores G, Smitz M-F, Hsu J, Chepynoga K, Eozenou P. Progress on impoverishing health spending in 122 countries: a retrospective observational study. Lancet Glob Health 2018;6:e180 92. doi:10.1016/S2214-109X(17)30486-2

36 Lake DA, Baum MA. The Invisible Hand of Democracy: Political Control and the Provision of Public Services. Comp Polit Stud 2001;34:587621. doi:10.1177/0010414001034006001

37 Wang Y, Mechkova V, Andersson F. Does Democracy Enhance Health? New Empirical Evidence 1900-2012. Polit Res Q 2019;72:554-69. doi:10.1177/1065912918798506

38 Besley T, Kudamatsu M. Health and Democracy. Am Econ Rev 2006;96:313-8. doi:10.1257/000282806777212053

39 Ghobarah HA, Huth P, Russett B. Comparative Public Health: The Political Economy of Human Misery and Well-Being. Int Stud Q 2004;48:73-94. doi:10.1111/j.0020-8833.2004.00292.x

40 Gerring J, Thacker SC, Alfaro R. Democracy and Human Development. Polit 2012;74:1-17. doi:10.1017/S0022381611001113

41 Mackenbach JP, Hu Y, Looman CWN. Democratization and life expectancy in Europe, 1960-2008. Soc Sci Med 2013;93:166-75. doi:10.1016/j.socscimed.2013.05.010

42 Miller MK. Electoral Authoritarianism and Human Development. Comp Polit Stud 2015. doi:https://doi.org/10.1177/0010414015582051

43 Kim NK, Kroeger AM. Do multiparty elections improve human development in autocracies?Democratization 2018;25:251-72. doi: 10.1080/13510347.2017.1349108

44 Kudamatsu M. Has Democratization Reduced Infant Mortality in Sub-Saharan Africa? Evidence from Micro Data. J Eur Econ Assoc 2012;10:1294-317. doi:10.1111/j.15424774.2012.01092.x

45 Leininger J, Lührmann A, Sigman R. The relevance of social policies for democracy: preventing autocratisation through synergies between SDG 10 and SDG 16. German Development Institute, 2019 doi:10.23661/dp7.2019

46 Levitsky S, Way LA. Competitive Authoritarianism: Hybrid Regimes after the Cold War. Cambridge University Press, 2010. doi:10.1017/ CBO9780511781353

47 Rahman M, Rob U, Noor FR, Bellows B. Out-of-pocket expenses for maternity care in rural Bangladesh: a public-private comparison. Int Q Community Health Educ 2012-2013;33:143-57. doi:10.2190/ IQ.33.2.d

Supplementary information: additional material 